\title{
Entre os Direitos Humanos e a Pressão Política: O Caso Belo Monte no Sistema Interamericano
}

\author{
Ademar Pozzatti Junior \\ Mestre e doutorando em Direito pela Universidade Federal \\ de Santa Catarina (UFSC). juniorpozzatti@gmail.com

\section{Luana Isis Ribeiro} \\ Mestranda em Direito pela Universidade Federal de Santa \\ Catarina (UFSC). ribeiroluanaisis@gmail.com
}

\begin{abstract}
Resumo
0 presente artigo tem por objetivo investigar a atuação do Sistema Interamericano de Direitos Humanos no caso da Usina Hidrelétrica de Belo Monte e a postura do Estado brasileiro diante da recomendação apresentada por meio da medida cautelar 382/2010 pela Comissão Interamericana de Direitos Humanos. Para tanto, primeiramente analisa-se o debate acerca da construção da Usina Hidrelétrica de Belo Monte no Pará e todos os aspectos que envolvem a suposta violação dos direitos humanos decorrentes dessa obra, especialmente os danos causados à identidade cultural de todas as populações atingidas. Na sequência serão investigados os fundamentos da petição inicial apresentada pelas organizações de Proteção de Direitos Humanos e Ambientais perante a Comissão Interamericana. Por fim serão analisados o conteúdo da Medida Cautelar 382/10 da Comissão Interamericana de Direitos Humanos, bem como a postura do Estado brasileiro diante dessa recomendação, o que resultou na sua revogação. Para alcançar o objetivo proposto utilizar-se-á o método de estudo de caso. Como método de pesquisa adotou-se o método bibliográfico e documental, especialmente a doutrina teórico-conceitual dos direitos humanos e os documentos oficiais relacionados a Belo Monte.
\end{abstract}

Palavras-chave: Direitos humanos. Sistema Interamericano de Direitos Humanos. Caso Belo Monte. 


\title{
Between Human Rights Political Pressure: The Belo Monte Case In The Interamerican System
}

\begin{abstract}
This paper aims to investigate the role of the Inter-American System of Human Rights in the case of Belo Monte Hydroelectric Plant and the attitude of the Brazilian government on the recommendation made by the Preliminary Injunction $382 / 2010$ by the Inter-American Commission on Human Rights. Therefore, the first part of this paper analyzes the debate on the construction of the Belo Monte hydroelectric plant in Pará and all aspects involving alleged human rights violations resulting from this construction, especially the damage caused to the cultural identity of all populations affected. Later, it will be studied the fundamentals of the petition presented by the non-governmental organizations of Environmental and Human Rights protection before the Inter-American Commission of Human Rights. Finally it will be analyzed the contents of the Preliminary Injunction 382/10 of the Inter-American Human Rights Commission, and the position of the Brazilian government against this recommendation, which resulou in its repeal. To achieve the proposed objective will be used, the method of case study. As a method of research, it is used the bibliographic and documentary method, especially theoretical-conceptual doctrine of Human Rights and official documents related to Belo Monte.
\end{abstract}

Keywords: Human rights. Inter-American Systen of Human Rights. Belo Monte Case.

\section{Sumário}

1 Introdução. 20 Projeto de Instalação da Usina Hidrelétrica de Belo Monte e as Violações aos Direitos Humanos. 30 Direito à Identidade Cultural no Sistema Interamericano. 4 A Petição das Organizações de Proteção de Direitos Humanos e Ambientais Perante a Comissão Interamericana. 5 A Medida Cautelar 382/10 da Comissão Interamericana de Direitos Humanos. 6 A Revogação da Medida Cautelar 382/10. 7 Conclusão. 8 Referências. 


\section{INTRODUÇÃO}

O Direito Internacional formou-se ao longo do século 20 sobretudo por meio da tutela dos direitos humanos, de um lado, e da tutela dos grandes interesses econômicos, de outro. Dessa forma, muitos instrumentos internacionais têm se dedicado a tutelar os direitos humanos nas mais diversas organizações internacionais universais e/ou regionais. Não raras vezes a concretização desses direitos é obstaculizada por interesses econômicos internacionais ou internos, gerando uma celeuma a ser decidida pelas mais diversas Cortes internacionais.

Este artigo trata justamente de uma dessas controvérsias, envolvendo a tutela dos direitos humanos das populações tradicionais do Alto Xingu que seriam violados com a construção da Usina Hidrelétrica de Belo Monte (UHBM), de um lado, e os interesses econômicos do Estado brasileiro e de grandes empreiteiras locais que se beneficiariam economicamente com a construção dessa que seria a maior obra da segunda fase do Programa de Aceleração do Crescimento (PAC-2) do governo federal. Este artigo, portanto, tem por objetivo apresentar a controvérsia da Usina Hidrelétrica de Belo Monte no Sistema Interamericano de Direitos Humanos (SIDH), verificando em que medida a jurisdição internacional cumpre o seu papel de constranger os Estados quando estes são uma fonte de violação de compromissos por eles mesmos assumidos.

Assim, o primeiro item deste artigo irá analisar o debate acerca do projeto de instalação e autorização de estudos de impactos ambientais para a construção da UHBM no Pará (Brasil), e seus iminentes riscos de violações de direitos humanos e degradações ambientais (2) Posteriormente serão investigados quais os compromissos firmados no Pacto de São José da Costa Rica que estariam sendo violados com a construção da UHBM, dando especial atenção ao direito à identidade cultural das populações indígenas que são afetadas com esta obra (3). 
No terceiro momento serão investigados os fundamentos da petição inicial apresentada por diversas organizações da sociedade civil que representaram os membros das comunidades indígenas da bacia do Rio Xingu solicitando à Comissão Interamericana de Direitos Humanos a concessão de medida cautelar a fim de obstar a construção da usina nas condições em que estava sendo edificada (4). Por fim, será analisado o conteúdo da medida cautelar 382/2010 recomendada ao Estado brasileiro (5), bem como a resposta do governo brasileiro perante o SIDH, que resultou na revogação da medida cautelar (6).

\section{O PROJETO DE INSTALAÇÃO DA USINA HIDRELÉTRICA DE BELO MONTE E AS VIOLAÇÕES AOS DIREITOS HUMANOS}

A proposta de construção da Usina Hidrelétrica de Belo Monte, situada na Volta Grande do Rio Xingu, no Pará, existe desde a década de 80 do século 20. A partir de então o referido projeto tem gerado inúmeros debates, sobretudo acerca dos impactos no meio ambiente e nas comunidades indígenas que ali residem. Em contraponto a isso existe a necessidade do país de aumentar a capacidade de fornecimento de energia elétrica, de maneira que possa atender à crescente demanda interna. Diante desse embate, diversos setores da sociedade civil levaram ao poder Judiciário a controvérsia que gerou incalculáveis discussões entre interesses públicos constitucionalmente protegidos, no entanto colidentes, mas de extrema relevância para toda a sociedade, como a proteção do meio ambiente e das comunidades indígenas e a necessidade crescente de produção de energia elétrica no país (Sena, 2012, p. 2).

Nesse sentido, Arlindo Butzke (2013, p. 257) leciona:

O caso da Usina Belo Monte repercutiu em diversos meios. Atores globais, entidades ambientalistas, caciques no exterior, presidentes de cocar, bem como outras situações midiáticas ocorreram neste longo 
processo histórico-político sobre a questão energética no Rio Xingu. Estudos são encontrados antes mesmo da promulgação da Constituição de 1988 sobre as potencialidades locais desta região da Amazônia Legal.

Segundo dispõe o artigo 231, $\S 3^{\circ}$, da Constituição Federal de 1988, o aproveitamento dos recursos hídricos em terras indígenas somente pode ser efetivado com autorização do Congresso Nacional, contanto que sejam ouvidas as comunidades afetadas.

Conforme a legislação brasileira, os povos indígenas atingidos pela construção do empreendimento deveriam ter sido consultados em duas ocasiões: primeiramente, antes da aprovação pelo Congresso Nacional para dar início ao empreendimento, bem como pelo poder Executivo durante o processo de avaliações e licenciamento do projeto (Aida, 2010, p. 27).

Por sua vez, o artigo 49, XVI e o artigo 62 , $3^{\circ}$, da Constituição Federal de 1988, preceitua que o Decreto Legislativo é o instrumento adequado para tratar de matérias que são de competência exclusiva do Congresso Nacional.

Diante disso, toda e qualquer eventual autorização de exploração de recursos naturais de reservas indígenas deve ser antecipadamente autorizada por meio de Decreto Legislativo. Logo, o processo de construção do complexo hidrelétrico de Belo Monte, situado em trecho do Rio Xingu, no Pará, teve início somente após a promulgação do Decreto Legislativo $\mathrm{n}^{0} 788$, de 13 de julho de 2005, pelo Congresso Nacional (Sena, 2012, p. 2).

Foi por meio do referido decreto $\mathrm{n}^{0} 788 / 05$, portanto, que o Congresso Nacional permitiu ao poder Executivo a construção da Usina Hidrelétrica de Belo Monte, contudo deveriam ser realizados estudos de viabilidade técnica, econômica, ambiental e antropológica, assim como a oitiva das comunidades indígenas afetadas pela referida obra (Sena, 2012, p. 3). 
O Decreto Legislativo $\mathrm{n}^{\mathrm{o}}$ 788/05 foi redigido da seguinte maneira:

Art. $1^{o}$ É autorizado o Poder Executivo a implantar o Aproveitamento Hidrelétrico Belo Monte no trecho do Rio Xingu, denominado "Volta Grande do Xingu”, localizado no Estado do Pará, a ser desenvolvido após estudos de viabilidade técnica, econômica, ambiental e outros que julgar necessários.

Art. $2^{\circ}$ Os estudos referidos no art. $1^{\circ}$ deste Decreto Legislativo deverão abranger, dentre outros, os seguintes:

I - Estudo de Impacto Ambiental - EIA;

II - Relatório de Impacto Ambiental - Rima;

III - Avaliação Ambiental Integrada - AAI da bacia do Rio Xingu; e

IV - estudo de natureza antropológica, atinente às comunidades indígenas localizadas na área sob influência do empreendimento, devendo, nos termos do $\S 3^{\circ}$ do art. 231 da Constituição Federal, ser ouvidas as comunidades afetadas.

Parágrafo único. Os estudos referidos no caput deste artigo, com a participação do Estado do Pará, em que se localiza a hidrelétrica, deverão ser elaborados na forma da legislação aplicável à matéria.

Art. $3^{\circ}$ Os estudos citados no art. $1^{\circ}$ deste Decreto Legislativo serão determinantes para viabilizar o empreendimento e, sendo aprovados pelos órgãos competentes, permitem que o Poder Executivo adote as medidas previstas na legislação objetivando a implantação do Aproveitamento Hidrelétrico Belo Monte (Brasil, 2005).

Na sequência da publicação do Decreto Legislativo $\mathrm{n}^{0}$ 788/05, a Procuradoria da República no Estado do Pará, o Instituto Socioambiental, a ONG Greenpeace, o Centro de Estudos das Populações da Região do Carajás e a Coordenação das Organizações Indígenas da Amazônia Brasileira solicitaram ao procurador geral da República que adotasse as devidas providências legais e imprescindíveis, a fim de anular o mencionado decreto (Sena, 2012, p. 3). 
A esse respeito, apresenta-se os ensinamentos de Butzke (2013, p. 257):

Com o assunto tomando as redes mundiais sobre a postura presidencial acerca do desalojamento das comunidades indígenas, bem como sobre a inundação dos milhares de hectares de Floresta Amazônica, movimentos humanos, sociais, culturais, ambientais, econômicos e jurídicos tentaram impedir os efeitos decorrentes do Decreto Legislativo Brasileiro.

Diante disso, no dia 26 de agosto de 2005 o procurador-geral da República ajuizou a Ação Direta de Inconstitucionalidade nº 3.573-DF com pedido de medida cautelar em razão do Decreto Legislativo $\mathrm{n}^{0}$ 788/05. Em síntese, o procurador-geral da República argumentou que o referido Decreto seria inconstitucional, uma vez que foi editado pelo Congresso Nacional sem a realização de audiências públicas para a oitiva das comunidades indígenas atingidas. Além disso, argumentou no sentido de que se tornaria inútil a oitiva das comunidades indígenas após a autorização do Decreto Legislativo, porquanto a decisão já teria sido tomada (Sena, 2012, p. 3).

O Supremo Tribunal Federal, porém, não conheceu da Ação Direta de Inconstitucionalidade $\mathrm{n}^{\circ} 3.573$, pois alegou que não era cabível ação direta contra lei-medida, diante do fato de se tratar de lei em sentido formal. Para a Suprema Corte o Decreto 788/05 seria, tão somente, uma autorização para o poder executivo dar início aos estudos necessários para a construção da Usina Hidrelétrica de Belo Monte (Sena, 2012, p.3).

Após a supramencionada decisão do Supremo Tribunal Federal, a fim de proteger os direitos do meio ambiente e das comunidades afetadas, o Ministério Público Federal interpôs inúmeras ações civis públicas para suspender o licenciamento por falta de licitação; assegurar a oitiva dos índios; evitar que os estudos de impacto ambiental deixassem de cumprir os requisitos legais; suspender liminarmente o leilão, solicitar audi- 
ências públicas, dentre outras. Além disso, também foi ajuizada ação de improbidade administrativa contra o funcionário do Ibama que autorizou a realização do leilão mesmo diante da escassez dos estudos de impacto ambiental (Aida, 2010, p. 36).

Cumpre informar que:

O juiz federal de Altamira, Antonio Carlos de Almeida Campelo, após analisar as justificativas e as provas apresentadas concedeu quatro vezes o pedido dos promotores. Entretanto, em grau de recurso e com uma rapidez que não é comum na Justiça brasileira, o Governo Federal conseguiu que o Presidente do Superior Tribunal de Justiça numa decisão unilateral derrubasse as decisões de Campelo o que permitiu o andamento do processo de licenciamento (Aida, 2010, p. 36-37).

Diante desse fato, o juiz Campelo foi retirado do caso, devido a uma decisão administrativa que resolveu criar uma nova Vara especializada em Direito Ambiental na capital, Belém. Deste modo, todas as ações envolvendo a construção da usina foram direcionadas para um novo juiz, Ruy Dias de Souza Filho, que coincidentemente não era especialista em matéria de Direito Ambiental (Aida, 2010, p. 38).

Após a publicação do Decreto de autorização do Aproveitamento Hidrelétrico Belo Monte, em 2005, iniciaram-se os processos de licitações, estudos de impactos, as contratações e um crescimento desorganizado na cidade de Altamira, Estado do Pará. Em razão disso o índice de criminalidade na cidade aumentou consideravelmente, porquanto o desenvolvimento segue voltado somente na órbita dos interesses econômicos. Por outro lado, quando questionado o poder público sobre as questões de saúde, educação, segurança e meio ambiente, a resposta é no seguinte sentido: não é possível acompanhar os passos destas obras faraônicas (Butzke, 2013, p. 257). 
Diante desse cenário retrógrado, inúmeras instituições de proteção ambiental disponibilizaram modelos de ações populares contra a usina com o intuito de propiciar a qualquer cidadão o exercício do princípio da cidadania. Uma das principais ações reflete o descaso e consequente desespero vivido pelas comunidades locais. Para Butzke, "O Xingu abriga o primeiro parque indígena do país, conhecido pelos seus expedicionistas Villa Lobos, e hoje a Amazônia recebe de braços atados um elefante branco disfarçado de Cavalo de Troia”. (2013, p. 257).

O Rio Xingu é um dos afluentes do Rio Amazonas e, após a instituição do complexo hidrelétrico se tornará cada vez mais vulnerável ao tráfico de animais silvestres, à extração de minérios e à biopirataria (Butzke, 2013, p. 257-258).

Assim sendo, a compreensão de qualquer questão que afeta os indígenas exige atenção dos direitos humanos e dos instrumentos internacionais de proteção, pois esses instrumentos é que asseguram a plena eficácia dos direitos ali elencados e isso só ocorre por intermédio de normas tuteladoras dos bens da vida. Por exemplo, a Declaração Universal dos Direitos Humanos de 1948, que foi ratificada pelo Brasil, possui força de emenda constitucional, e assim deve ser assegurada (Butzke, 2013, p. 26).

\section{O DIREITO À IDENTIDADE CULTURAL NO SISTEMA INTERAMERICANO}

A identidade cultural foi considerada um aglomerado de parâmetros culturais por meio do qual um indivíduo ou um grupo se caracteriza e se manifesta e de como pretende ser aceito e respeitado. Do mesmo modo, requer as liberdades inerentes à dignidade da pessoa, pois unifica em um processo constante a diversidade cultural com o particular e o universal, 
a memória e o projeto. Trata-se de uma representação intersubjetiva que traz um norte para a maneira de sentir, perceber e do agir das pessoas no mundo (Chiriboga, 2006, p. 44-45).

Como elemento integrante da identidade cultural existe o patrimônio imaterial, que deve ser entendido como aquilo que faz parte da identidade de um povo, mas que também possa ser dividido com diversos povos, se esse for o desejo daqueles. O patrimônio cultural pode ser classificado em tangível e intangível. O primeiro alude aos bens, móveis ou imóveis, que tenham amplo significado para o patrimônio cultural dos povos; Já no que diz respeito ao patrimônio intangível, impede mencionar o artigo 2.1 da Convenção da Unesco para Salvaguarda do Patrimônio Cultural Imaterial:

Art. 2.1 - Entende-se por "patrimônio cultural imaterial" as práticas, representações, expressões, conhecimentos e técnicas - junto com os instrumentos, objetos, artefatos e lugares culturais que lhes são associados - que as comunidades, os grupos e, em alguns casos, os indivíduos reconhecem como parte integrante de seu patrimônio cultural. Este patrimônio cultural imaterial, que se transmite de geração em geração, é constantemente recriado pelas comunidades e grupos em função de seu ambiente, de sua interação com a natureza e de sua história, gerando um sentimento de identidade e continuidade e contribuindo assim para promover o respeito à diversidade cultural e à criatividade humana. Para os fins da presente Convenção, será levado em conta apenas o patrimônio cultural imaterial que seja compatível com os instrumentos internacionais de direitos humanos existentes e com os imperativos de respeito mútuo entre comunidades, grupos e indivíduos, e do desenvolvimento sustentável (Unesco, 2003).

Basicamente o direito à identidade cultural consiste no direito de todo grupo étnico-cultural e seus integrantes de fazerem parte de uma determinada cultura e, consequentemente serem aceitos e reconhecidos como diferentes, porém tendo o direito de preservar sua própria identi- 
dade e patrimônio cultural tangível e intangível. Além disso, possuem o direito de não serem coagidos a se tornarem integrantes de outra cultura ou de ser assimilado, involuntariamente, por ela (Chiriboga, 2006, p. 45).

Por outro lado, o direito à identidade cultural também incide na transformação, na adequação e no agrupamento de outras culturas e povos, contanto que isso ocorra de forma voluntária, livre e determinada por parte do grupo (2006, p. 46).

Diante disso, convém evidenciar os comentários acerca do fortalecimento da identidade cultural:

[...] O fortalecimento da identidade cultural não tem como único objetivo conservar culturas, mas impulsionar o desdobramento de suas potencialidades no presente e no futuro, permitir o exercício dos direitos culturais, estabelecer canais mais justos de diálogo e participação na tomada de decisões, e evitar processos de interação avassaladores entre diferentes culturas. Também deve-se destacar que, por sua própria natureza, o DIC é um direito autônomo, dotado de singularidade própria (ao menos conceitualmente), mas, ao mesmo tempo, é um "direito síntese", que abrange (e atravessa) tanto direitos individuais como coletivos (Chiriboga, 2006, p. 46).

Para isso, tornam-se necessários a efetivação e o pleno exercício de todos os direitos humanos internacionalmente assegurados, que por sua vez são dependentes de muitos outros direitos (Chiriboga, 2006, p. 46).

Acerca do assunto cabe observar o seguinte comentário exposto no artigo $4^{\circ}$ da Declaração Universal da UNESCO, bem como o artigo 2.1 da Convenção sobre a Proteção e Promoção da Diversidade Cultural, in verbis:

O art. 4 da Declaração Universal da Unesco sobre a diversidade cultural dispõe que a defesa da diversidade cultural é um imperativo ético, inseparável do respeito à dignidade da pessoa. Implica o compromisso de respeitar os direitos humanos e as liberdades fundamentais, em par- 
ticular, os direitos das pessoas que pertencem a minorias e os direitos dos povos autóctones. No mesmo sentido, a CIDH considerou que para que um grupo étnico possa subsistir preservando seus valores culturais, é fundamental que seus componentes possam gozar de todos os direitos reconhecidos pela Convenção Americana sobre Direitos Humanos, pois dessa forma, garante seu efetivo funcionamento como grupo, o que inclui a preservação de sua identidade cultural. Finalmente, o artigo 2.1 da Convenção sobre a Proteção e Promoção da Diversidade das Expressões Culturais, de 2005, dispõe: Só se poderá proteger e promover a diversidade cultural se estiverem garantidos os direitos humanos e as liberdades fundamentais (Unesco, 2003).

Sob o ponto de vista do sistema interamericano a proteção do direito à identidade cultural está calcada no Artigo $5^{\circ}$ da Convenção Americana de Direitos Humanos, no direito à integridade pessoal, que compreende a integridade física, psíquica e moral. No que respeita à integridade física, o artigo $5^{\circ}$ da Convenção Americana, em consonância com o artigo $10^{\circ}$ do Protocolo de San Salvador, que dispõe sobre o direito à saúde, fazem a ponte com o direito à identidade cultural, que por sua vez abrange $o$ direito dos grupos étnico-culturais e seus integrantes de manter, valer-se e resguardar suas próprias medicinas e métodos de saúde habituais. Ademais, os supramencionados grupos possuem o direito de exigir que os serviços de saúde pública estejam de acordo com o enfoque cultural (Chiriboga, 2006, p. 52).

No tocante ao respeito à integridade psíquica e moral, convém lembrar o caso dos Guarani- Kiowah:

Uma nação de 26.000 membros no Estado de Mato Grosso do Sul, no Brasil, onde ocorreu um fenômeno sequiencial de suicídios, cuja proporção era 30 vezes maior à média nacional. Os suicídios ocorreram por causa da profunda depressão dos indígenas pela perda de seus territórios tradicionais (Chiriboga, 2006, p. 53). 
Em outras palavras, para diversas comunidades indígenas a rescisão dos laços ancestrais, o desmembramento de seus vínculos com a terra e seus recursos naturais, bem como a renúncia coagida de suas práticas culturais enseja um sofrimento cruel, que indubitavelmente compromete seu direito à integridade psíquica e moral (2006, p. 53) .

Sobre os direitos políticos dos grupos étnicos-culturais na concepção do SIDH apresentados na Convenção Americana de Direitos Humanos, importa observar:

[...]o DIC dos grupos étnico-culturais e seus membros, visto através do artigo 23 (direitos políticos) da $\mathrm{CADH}$, abrange (a) o direito de participar livremente em todos os níveis de decisões em instituições públicas responsáveis por políticas e programas que os afete. $\mathrm{O}$ direito de ser consultado cada vez que se prevejam medidas legislativas, administrativas ou de qualquer outro tipo que possa afetá-los; (b) o direito de decidir sobre suas próprias prioridades de desenvolvimento, bem como sobre qualquer questão relacionada a seus assuntos internos; (c) o direito de manter e desenvolver seus próprios sistemas políticos e econômicos e de manter e desenvolver suas próprias instituições decisórias. Em conjunto com o artigo 13 (liberdade de pensamento e de expressão) da CADH, está também protegido o seu direito de receber informação oportuna, clara e veraz, de todos os fatos que lhes digam respeito para que, assim, possam se pronunciar individual ou coletivamente (Chiriboga, 2006, p. 58-59).

Sendo assim, torna-se evidente que os Estados precisam avaliar que os povos indígenas carecem de um vasto grau de autodeterminação e domínio acerca do seu próprio destino político, uma vez que a maior preocupação desses povos é a proteção de sua cultura (2006, p. 56).

Vale lembrar sobre o direito à propriedade dos povos indígenas a partir do olhar da Convenção Americana e sua respectiva interpretação de seu artigo 21: 
[...] poderíamos interpretar que a proteção que o artigo 21 da $\mathrm{CADH}$ dá ao DIC compreende o direito dos povos indígenas do uso e gozo de seus bens, tanto materiais como imateriais. Isso implica o direito de conservar, utilizar, controlar, reivindicar e proteger seu patrimônio cultural material e imaterial, bem como todo tipo de produto ou fruto de sua atividade cultural e intelectual, seus procedimentos, tecnologias e instrumentos próprios e lugares onde sua cultura se expressa e desenvolve (Chiriboga, 2006, p. 60).

A proteção elencada no artigo 21 da Convenção Americana é reforçada pelo artigo 12, também da Convenção Americana, o qual versa sobre a liberdade de consciência e religião, sobretudo nos casos em que os bens materiais ou imateriais desses povos possuírem significados religiosos ou espirituais (2006, p. 60).

Corroborando com o que foi exposto acerca do Direito à Identidade Cultural dos povos indígenas, é forçoso salientar os comentários de Letícia Borges da Silva:

Os povos indígenas detêm um modo de produção diferenciado, baseado em atividades de baixo impacto ambiental e na sustentabilidade ecológica dos recursos explorados. Ao longo dos tempos, as comunidades indígenas desenvolveram-se através de um profuso contato com o meio ambiente, e assim puderam aprender métodos de utilização da biodiversidade, desenvolvendo remédios, cosméticos e alimentos. Além disso, manejam os recursos naturais e contribuem para a manutenção da riqueza biológica, tendo uma importante função na preservação ambiental. Por tudo isso, mantêm em seus territórios uma alta concentração de recursos naturais.

Com o crescimento capitalista e a busca pelo desenvolvimento econômico a qualquer custo, muitos países, como o Brasil e os Estados Unidos, expandiram suas economias, e a procura por terras e recursos naturais (madeira, água, plantas, animais) aumentou progressivamente. Certamente essa demanda atingiu as terras indígenas devido à vasta riqueza ali contida. Com o decorrer do tempo, o problema se agravou, 
pois a população indígena aumentava ao passo que os recursos naturais diminuíam, comprometendo então a sobrevivência e a autossustentabilidade desses povos (Silva, 2011, p. 124).

Por isso, as organizações indígenas sentiram a necessidade de lutar para obterem melhor qualidade de vida, o direito à demarcação dos seus territórios, respeito a sua cultura, língua e tradições. Outrossim, defendem que suas comunidades devem ter assegurado o direito ao seu desenvolvimento econômico autônomo e sustentável, a inserção desses povos em programas de bem-estar social e, sobretudo, a possibilidade efetiva de manutenção da diversidade cultural (Silva, 2011, p. 125).

\section{A PETIÇÃO DAS ORGANIZAÇÕES DE PROTEÇÃO DE DIREITOS HUMANOS E AMBIENTAIS PERANTE A COMISSÃO INTERAMERICANA}

No ano de 2011, em nome das comunidades indígenas da Bacia do Rio Xingu, sete organizações da sociedade civil, quais sejam, o Movimento Xingu Vivo Para Sempre (MXVPS), Coordenação das Organizações Indígenas da Amazônia Brasileira (Coiab) Prelazia do Xingu, Conselho Indigenista Missionário (Cimi), Sociedade Paraense de Direitos Humanos (SDDH), Justiça Global, Asociación Interamericana para la Defensa del Ambiente (Aida), solicitaram à CIDH, em consonância com o estabelecido no artigo 25 do Regulamento da Comissão, a concessão de medidas cautelares em favor das comunidades indígenas da bacia do Rio Xingu (Aida, 2010, p. 1).

Isso somente ocorreu devido ao esgotamento e à ineficácia das medidas solicitadas ao Brasil na tentativa de impedir a construção da Usina Hidrelétrica. Assim, tornou-se necessário recorrer à Comissão Interamericana de Direitos Humanos (CmIDH) com o intuito de evitar a concretização das possíveis violações de direitos humanos (Aida, 2010, p. 2). 
O Sistema Interamericano de Direitos Humanos, composto pela Comissão e pela Corte Interamericanas de Direitos Humanos (CrIDH) possui natureza de atuação complementar, que se caracteriza diante do estabelecido no artigo 46 da Convenção Americana de Direitos Humanos.

Art. 46.1- Para que uma petição ou comunicação apresentada de acordo com os artigos 44 ou 45 seja admitida pela Comissão, será necessário: a. que hajam sido interpostos e esgotados os recursos da jurisdição interna, de acordo com os princípios de direito internacional geralmente reconhecidos (OEA, 1969).

Oportuno dizer que a Comissão Interamericana de Direitos Humanos, no caso do Povo Saramaka vs. Suriname, interpretou como obrigatória a consulta prévia quando se tratarem de planos de desenvolvimento ou investimento em larga escala que possam provocar impactos nos territórios tradicionais, com o consentimento livre, prévio e informado sendo condição indispensável para sua realização (Moreira, 2014, p. 129).

Moreira ressalta inclusive que a ausência de consulta prévia já foi considerada pela Corte Interamericana de Direitos Humanos como discriminação de fato contra um povo indígena que foi marginalizado no gozo de seus direitos (2014, p. 129).

Nessa linha, em resumo, a denúncia que foi levada à CIDH tratou a respeito de iminentes e irreparáveis violações de direitos humanos às comunidades supramencionadas, direitos estes protegidos pela Convenção Americana de Direitos Humanos. A situação vivida pelas referidas comunidades é extremamente grave, pois,

este projeto ameaça impactar irremediavelmente a vida e a integridade dos indígenas e ribeirinhos que ali vivem tendo em vista o deslocamento forçado, a insegurança alimentar e hidrológica, com a perda de água potável, o aumento de doenças, ameaças de invasões às terras indígenas e $o$ aproveitamento ilegal de recursos naturais, $o$ aumento da pobreza e a migração desordenada, que sobrecarregará os sistemas de 
saúde, educação e segurança pública. Apesar da gravidade e irreversibilidade dos impactos da obra para as comunidades locais, não foram realizadas as medidas adequadas para garantir a proteção dos direitos das mesmas nem do meio ambiente (Aida, 2010, p. 2).

Assim, os peticionários solicitaram à Comissão Interamericana que recomendasse ao Estado Brasileiro a adoção das seguintes medidas cautelares em favor das comunidades supramencionadas (Aida, 2010, p. 41):

- A suspensão imediata do processo de licenciamento ambiental referente à UHE Belo Monte.

- A interrupção de qualquer intervenção, atividade ou procedimento por parte do Estado brasileiro ou por terceiras pessoas para a construção da UHE de Belo Monte.

- Respeitar os direitos humanos das pessoas e comunidades afetadas em tudo que seja relacionado com o projeto (Aida, 2010, p. 41).

Convém relembrar que a competência da Comissão Interamericana para editar medidas cautelares é baseada no artigo 25 do seu Estatuto, que assim dispõe:

4. A CmIDH considerará a gravidade e urgência da situação, seu contexto, e a iminência do dano em questão ao decidir sobre se corresponde solicitar a um Estado a adoção de medidas cautelares. A CmIDH também levará em conta: a. se a situação de risco foi denunciada perante as autoridades competentes ou os motivos pelos quais isto não pôde ser feito; b. a identificação individual dos potenciais beneficiários das medidas cautelares ou a determinação do grupo ao qual pertencem; e c. a explícita concordância dos potenciais beneficiários quando o pedido for apresentado à $\mathrm{CmIDH}$ por terceiros, exceto em situações nas quais a ausência do consentimento esteja justificada (Ventura; Cetra, 2012, p. 19). 
$\mathrm{Na}$ supramencionada petição apresentada perante a Comissão Interamericana observa-se que os requisitos elencados no artigo 25 do seu Estatuto foram preenchidos, uma vez que a gravidade e urgência da situação caracterizam- se pela iminência do início da construção, que se apresentou devido às declarações das autoridades brasileiras à decisão do Conselho Gestor do Ibama acerca da viabilidade ambiental do projeto de construção da UHE Belo Monte, bem como por meio da autorização da abertura de Picada concedida pelo Ibama e a entrega do Plano Básico Ambiental pelo Consórcio (Aida, 2010, p. 39).

Já os danos irreparáveis às comunidades locais caracterizam-se pela violação do direito à vida, à integridade e à saúde, em razão da alta probabilidade do crescimento de doenças graves, insegurança alimentar e hidrológica, a retirada das comunidades de suas propriedades e sua consequente perda de território, sobretudo das comunidades tradicionais, e migração desordenada em virtude do início das obras. Além disso, o Estado brasileiro não tem garantido que sejam realizados todos os estudos necessários tendentes a impedir os numerosos impactos que serão causados caso nada seja feito (Aida, 2010, p. 39).

Ressalta-se que é a terceira vez que o governo brasileiro tenta construir uma barragem na área do Rio Xingu. Diante disso cumpre mencionar os esclarecimentos apresentados pelos peticionários à $\mathrm{CIDH}$ sobre a origem do projeto do complexo Belo Monte (Aida, 2010, p. 5).

O projeto inicial, anteriormente nomeado de represa de Kararaô, foi apresentado no final dos anos 70 durante a ditadura militar. Por razão das mobilizações nacionais e internacionais lideradas pelos indígenas Kayapó, que manifestaram sua oposição pelos possíveis impactos ambientais e sociais que se gerariam, o governo suspendeu o projeto. Em 1999, iniciou-se uma segunda tentativa de implementação do megaprojeto. Uma equipe de pesquisadores, da Fundação de Amparo e Desenvolvimento da Pesquisa (Fadesp) da Universidade Federal do Pará (UFPA), foi contratada por membros do governo para realizar 
avaliações de impacto ambiental, a fim de cumprir uma das exigências do processo de licenciamento ambiental estadual que seria efetuado pela Secretaria Executiva de Ciência, Tecnologia e Meio Ambiente do Estado do Pará (Sectam). Os termos deste acordo e a tentativa de obter uma licença ambiental no âmbito estadual levaram ao ajuizamento de uma ação civil pública pelo Ministério Público Federal, cuja decisão garantiu a suspensão do processo de licenciamento ambiental. Entretanto, em 22 de janeiro de 2007, durante o seu segundo mandato, o presidente Luiz Inácio Lula da Silva resolveu retomar o projeto da represa de Kararaô, renomeado-o Belo Monte e usando-o como parte do Programa de Aceleração de Crescimento (PAC) do seu governo. Assim, o processo de licenciamento foi retomado, e o Estudo de Impacto Ambiental (EIA) foi conduzido pelo órgão federal responsável de assuntos ambientais, o Instituto Brasileiro do Meio Ambiente e dos Recursos Naturais (Ibama) (Aida, 2010, p. 5).

No que respeita ao polêmico processo de licenciamento ambiental, no ano de 2010 o Ibama concedeu a licença prévia mesmo diante da insuficiência dos dados apresentados. A par disso, o MPF entrou com mais uma ação judicial contra o governo, fundamentada em sete irregularidades. Entre elas, destaca-se o volume de água que será liberado no trecho de cem quilômetros da Volta Grande do Xingu, por onde o rio não mais passará em virtude de um desvio, tendo em vista que se trata de uma região na qual habitam pelo menos 12 mil famílias e 372 espécies de peixes (Pontes, 2011, p. 105).

Em comentário a essa questão, cabe destacar as explanações dos peticionários junto a $\mathrm{CIDH}$.

[...] as observações feitas por outro painel de especialistas independentes, técnicos do Instituto Brasileiro do Meio Ambiente e dos Recursos Naturais Renováveis (Ibama), apontaram através do Parecer $\mathrm{N}^{\circ}$ 114/2009 - Ibama, de 23 de novembro de 2009, que em "vista do prazo estipulado pela Presidência, esta equipe não concluiu sua análise a contento. Algumas questões não puderam ser analisadas na profundidade apropriada, dentre elas as questões indígenas e as contribuições das 
audiências públicas”. Não obstante, a Licença Prévia (LP) Ambiental foi outorgada pelo Ibama, no dia 1 de fevereiro de 2010, revelando a forte vontade política do Estado brasileiro em implementar o projeto de UHE Belo Monte em brevíssimo tempo e a falta de análise e avaliação do projeto a contento (Aida, 2010, p. 6).

Conforme todos os apontamentos técnicos elaborados, pelo Ibama ou pelas construtoras responsáveis pelos estudos, pela Funai, pelo MPF ou os cientistas que tiveram envolvimento com o estudo do projeto, tornou-se evidente que após a construção da usina de Belo Monte parte considerável da biodiversidade na região da Volta Grande do Xingu vai ser extinta. Esse trecho do Xingu, por meio do decreto do Ministério do Meio Ambiente, foi considerado como de alto significado biológico, em razão da presença de populações animais que vivem somente nessa área, imprescindíveis para a segurança alimentar, bem com para a economia dos povos que habitam essa região. A vazão que será reduzida, contudo, vai gerar a diminuição dos lençóis freáticos, o aniquilamento de inúmeras espécies de peixes, aves, quelônios, e o possível arrasamento da floresta aluvial, além de um aumento significativo do número de insetos transmissores de doenças (Pontes, 2011, p. 107).

Pontes (2011, p. 106) assinala ainda:

O parecer do Ibama demonstra, em 250 páginas, que a precariedade do atendimento às condicionantes existentes na época da expedição da licença provisória continuava no momento da publicação da licença de instalação: as condicionantes de saúde, educação, saneamento, levantamentos das famílias atingidas e navegabilidade não foram cumpridas pelo empreendedor. Mais grave: o relatório em que o empreendedor informou várias obras para saúde e educação que a vistoria dos técnicos no início de maio constatou simplesmente não existirem.

Mesmo diante dessas irregularidades, entretanto, o Ibama concedeu a licença de instalação, com base em argumentos inexistentes na lei ambiental, como ao se referir às condicionantes não cumpridas como 
condições em cumprimento ou parcialmente atendidas. Nessa linha, a Norte Energia não iniciou as obras de saneamento básico prometidas para a região na qual ficarão os canteiros da obra, porém exibiu um projeto com previsão de conclusão em março de 2012. O Ibama, por sua vez, considerou a condicionante em cumprimento ao invés de considerá-la não atendida (Pontes, 2011, p. 106).

\section{A MEDIDA CAUTELAR 382/10 DA COMISSÃO INTERAMERICANA DE DIREITOS HUMANOS}

Em resposta ao pleito das organizações sociais, que se manifestaram em prol das comunidades indígenas e ribeirinhas afetadas e, posteriormente, ao exame de admissibilidade da mencionada petição no dia $1^{0}$ de abril de 2011, a CmIDH concedeu a medida cautelar 382/10 em benefício dos membros das comunidades indígenas da bacia do Rio Xingu, no Pará, Brasil. Os peticionários declararam que sua vida e sua integridade pessoal corriam risco diante do grande impacto que todos sofreriam com a construção da usina hidrelétrica Belo Monte. Em síntese, conforme já mencionado, as principais apreensões dos índios envolveriam a perda dos peixes, das praias e das casas, ao aumento da incidência de doenças e da violência, até a perda da paisagem e das ilhas (Ventura; Cetra, 2013, p. 36).

Nesse contexto, o expediente das comunidades indígenas ao SIDH não é novidade, porquanto o Estado brasileiro em meados dos anos 80 já havia sido notificado pela Comissão Interamericana em múltiplos casos vinculados aos índios Yanomami (Ventura; Cetra, 2013, p. 34)

A busca pela tutela de proteção dos direitos humanos em âmbito internacional, mais precisamente perante o SIDH exterioriza a clara transnacionalização de um movimento político e de uma demanda que esgotou seus limites no plano nacional. Neste caso, porém, há uma particularidade com relação ao papel do Estado nesta demanda, pois é evidente que não 
está em pauta o dissenso federativo, uma vez que a edificação da hidrelétrica de Belo Monte é um projeto auspiciado pela União, como elemento do Programa de Aceleração do Crescimento - PAC (Ventura; Cetra, 2013, p. 36).

No que concerne ao Programa de Aceleração do Crescimento:

Segundo o Ministério da Fazenda, o PAC "consiste em um conjunto de medidas destinadas a: incentivar o investimento privado; aumentar o investimento público em infraestrutura e remover obstáculos burocráticos, administrativos, normativos, jurídicos e legislativos ao crescimento". O programa mescla "elementos da antiga agenda das reformas liberalizantes com o incremento do investimento, por meio de incentivos públicos diretos e indiretos", graças a uma autoproclamada "ação firme do governo federal”. A usina de Belo Monte é um dos elementos do eixo energético do PAC: quando concluída, seria "a terceira maior usina de geração de energia elétrica do mundo”. A atual Presidenta, Dilma Rousseff, já era apresentada, quando Ministra, como “mãe do PAC” (Ventura; Cetra, 2013, p. 36-37).

Nessa ordem de acontecimentos, parece não haver dúvidas de que, depois de abril de 2011, a Comissão Interamericana passou a ser compreendida pelo Brasil como certo entrave ao crescimento do país, tendente a ser extraído. É incorreto, todavia, afirmar que há um consenso no seio das instituições brasileiras acerca do caso Belo Monte, uma vez que somente o Ministério Público Federal já ajuizou inúmeras ações judiciais, concernentes à legalidade do processo de licenciamento da obra, a respeito da legislação ambiental, à oitiva e à remoção de povos indígenas, entre outras questões. Torna-se evidente que a litigância em âmbito interno não tem assegurado a tutela dos direitos das comunidades em litígio, e que o progresso na edificação da usina vai afetando, gradativamente, as possibilidades de reversão dos danos (Ventura; Cetra, 2013, p. 37). 
Logo, diante desse cenário, a Comissão Interamericana de Direitos Humanos outorgou a medida cautelar 382/2010 em favor dos membros das comunidades indígenas da bacia do Rio Xingu:

A CmIDH solicitou ao Governo Brasileiro que suspenda imediatamente o processo de licenciamento do projeto da Usina Hidrelétrica de Belo Monte e impeça a realização de qualquer obra material de execução até que sejam observadas as seguintes condições mínimas: (1) realizar processos de consulta, em cumprimento das obrigações internacionais do Brasil, no sentido de que a consulta seja prévia, livre, informativa, de boa-fé, culturalmente adequada, e com o objetivo de chegar a um acordo, em relação a cada uma das comunidades indígenas afetadas, beneficiárias das presentes medidas cautelares; (2) garantir, previamente, a realização dos citados processos de consulta, para que a consulta seja informativa, que as comunidades indígenas beneficiárias tenham acesso a um Estudo de Impacto Social e Ambiental do projeto, em um formato acessível, incluindo a tradução aos idiomas indígenas respectivos; (3) adotar medidas para proteger a vida e a integridade pessoal dos membros dos povos indígenas em isolamento voluntário da bacia do Xingu, e para prevenir a disseminação de doenças e epidemias entre as comunidades indígenas beneficiárias das medidas cautelares como consequência da construção da hidrelétrica Belo Monte, tanto daquelas doenças derivadas do aumento populacional massivo na zona, como da exacerbação dos vetores de transmissão aquática de doenças como a malária (CmIDH, 2011).

Em seguida, mais precisamente no dia 5 de abril de 2011, após o recebimento da medida cautelar, o Ministério das Relações Exteriores do Brasil despachou uma nota de incomum hostilidade:

O Governo brasileiro tomou conhecimento, com perplexidade, das medidas que a CmIDH de Direitos Humanos (CIDH) solicita sejam adotadas para "garantir a vida e a integridade pessoal dos membros dos povos indígenas” supostamente ameaçados pela construção da Usina Hidrelétrica de Belo Monte. O Governo brasileiro, sem minimizar a relevância do papel que desempenham os sistemas internacionais de 
proteção dos direitos humanos, recorda que o caráter de tais sistemas é subsidiário ou complementar, razão pela qual sua atuação somente se legitima na hipótese de falha dos recursos de jurisdição interna. A autorização para implementação do Aproveitamento Hidrelétrico de Belo Monte foi concedida pelo Congresso Nacional por meio do Decreto Legislativo n.788/2005, que ressalvou como condição da autorização a realização de estudos de viabilidade técnica, econômica e ambiental, em especial "estudo de natureza antropológica, atinente às comunidades indígenas localizadas na área sob influência do empreendimento”, com a devida consulta a essas comunidades. Coube aos órgãos competentes para tanto, IBAMA e FUNAI, a concretização de estudos de impacto ambiental e de consultas às comunidades em questão, em atendimento ao que prevê o parágrafo $3^{\circ}$ do artigo 231 da Constituição Federal. O Governo brasileiro está ciente dos desafios socioambientais que projetos como o da Usina Hidrelétrica de Belo Monte podem acarretar. Por essa razão, estão sendo observadas, com rigor absoluto, as normas cabíveis para que a construção leve em conta todos os aspectos sociais e ambientais envolvidos. O Governo brasileiro tem atuado de forma efetiva e diligente para responder às demandas existentes (Brasil, 2014b).

Diante desse cenário, ocorreram incontáveis explanações aos meios de comunicação, por autoridades governamentais, parlamentares, porta-vozes de empresa e partidos políticos que hostilizaram o SIDH. Nessa época a então secretária de Direitos Humanos, a ministra Maria do Rosário, pronunciou-se argumentando no sentido de que nunca faltou diálogo com as comunidades tradicionais, bem como com os povos indígenas. Além disso, ressaltou que existem inúmeras ações em andamento no poder Judiciário, portanto há um envolvimento de todos os poderes da República, por isso considerou que a Comissão de Direitos Humanos se precipitou na sua atuação (Ventura; Cetra, 2013, p. 39).

Convém evidenciar as declarações do ministro de Minas e Energia, Edison Lobão, que na oportunidade declarou que o governo brasileiro não necessitava de mais fiscalização para determinar o que precisa ou não ser 
concretizado para majorar a capacidade de produção de energia elétrica no país, pois o Brasil necessita urgentemente desta obra (Ventura; Cetra, 2013, p. 40).

No Congresso Nacional, a medida cautelar 382/2010 foi encarada como uma medida absurda, sem nexo e invasiva, porquanto os argumentos foram no sentido de que a decisão da construção da usina diz respeito à soberania do Brasil (Ventura; Cetra, 2013, p. 40).

Nesse mesmo sentido, ressalta-se a manifestação oficial do Partido Comunista do Brasil (PCdoB), que teceu declarações considerando o conteúdo da medida cautelar imposta pela $\mathrm{CmIDH}$, intempestivo, desarrazoado e inoportuno, sobrepondo:

A Comissão da OEA, cuja missão de defesa dos direitos humanos tem caráter suplementar à dos Estados nacionais que a compõem, nesse caso claramente ultrapassou sua competência. É lamentável que um órgão multilateral se deixe instrumentalizar por interesses mal-intencionados. Este inusitado pronunciamento se verifica num contexto em que a OEA perde relevância, sobretudo por ser conhecida entre os povos latino-americanos como "ministério das Colônias" dos Estados Unidos - dado seu nefasto papel histórico de suporte e braço da ação norte-americana na região. (...) Em especial, quanto à questão de respeito e de proteção de sua população indígena, o Brasil não reconhece em nenhuma autoridade externa condições para criticar ou orientar suas políticas. (...) A manifestação da OEA se soma a outras pressões exógenas que visam constranger o desenvolvimento sustentável do Brasil (PCdoB apud Ventura; Cetra, 2013, p. 40).

Não havia antecedentes de rechaço na relação entre o Estado brasileiro e os sistemas internacionais de proteção de direitos humanos como ocorreu neste caso. Assim, o embate internacional provocou tensões diplomáticas entre o governo brasileiro e a OEA (Ventura; Cetra, 2013, p. 36). 
Para Ventura e Cetra (2013, p. 41), primeiramente as reações de rechaço, do ponto de vista institucional, ao sistema interamericano partiram do poder Executivo, mas logo veio em seu apoio o poder Legislativo, pois em 9 de junho de 2011, por iniciativa da Comissão de Relações Exteriores e Defesa Nacional, a assembleia do Senado Federal acatou o voto de apoio ao governo brasileiro e de repreensão à $\mathrm{CmIDH}$.

Nesse sentido, afirmam os breves votos do Senado Federal:

Já se completaram doze anos de estudos e negociações, ouvidos vários segmentos da sociedade brasileira, para que se chegasse à decisão para o início das obras da usina de Belo Monte, iniciativa que certamente trará grandes benefícios à região. Nesse sentido, além da consulta aos distintos grupos interessados no projeto, foram realizados estudos de impacto socioambiental, dentro da tradição brasileira na construção de grandes obras de engenharia, e em conformidade com a legislação brasileira. (...) Certamente, o governo brasileiro mostra-se atento a todas essas questões sociais e de meio ambiente, às disposições legais e às particularidades e necessidades das populações que habitam a região onde será construída Belo Monte. Entendemos que a OEA precipitou-se em sua manifestação, chegando mesmo a envolver-se em assuntos internos do Brasil, o que vai de encontro a princípios basilares do Direito Internacional (Senado Federal, 2011, p. 22954-5).

Depreende-se nesse sentido que o princípio norteador de Direito Internacional referido pelos supramencionados votos seria o da não ingerência nas questões internas dos Estados. O Direito Internacional, contudo, não está focado somente na análise do trabalho dos sistemas regionais de proteção dos direitos humanos sob a ótica da intervenção. "Bem ao contrário, a afirmação paulatina do direito internacional dos direitos humanos é, de regra, felicitada pela doutrina internacionalista” (Ventura; Cetra, 2013, p. 41). 


\section{A REVOGAÇÃO DA MEDIDA CAUTELAR 382/10}

No entendimento de Ventura e Cetra (2013, p. 43), em uma entrevista significativamente importante para a compreensão do caso em tela concedida pelo secretário-geral da OEA, José Miguel Insulza, este ponderou como justa a reação do Brasil em relação à recomendação da medida cautelar e declarou que possivelmente a CIDH reavaliaria sua posição acerca do caso Belo Monte. Além disso, ressaltou que a Comissão Interamericana é completamente autônoma em relação à OEA, uma vez que é a CIDH que se pronuncia a respeito das matérias de direitos humanos.

Observa-se, no entanto, no relatório anual da CIDH de 2011 que

... há uma área na qual o terreno é realmente complicado. Quando a $\mathrm{CmIDH}$ começou a atuar nesses temas, quase como um tribunal, ainda que não tenha força obrigatória, os temas de que falava eram homicídio, tortura, desaparecimento, cárcere, etc. $\mathrm{O}$ surgimento dos temas ambientais e dos povos nativos abre um espaço que deve ser tratado com muito cuidado. Não creio que nenhum governo democrático tenha a intenção de criar problemas aos seus povos nativos. Acho que o pior que se pode fazer neste caso é exacerbá-lo e tratar o tema como se um fosse a vítima, e os outros a ditadura, como ocorreu a princípio. Espero que Belo Monte sirva para calibrar bem a coisa e entender que, quando se trata de projetos dessa envergadura, a $\mathrm{CmIDH}$ pode perfeitamente chegar aos governos para dar assessoria, opiniões, mas não tratar como um tema semijudicial (CmIDH, 2011, p. 83).

Conforme, a previsão de Insulza, no dia 29 de julho de 2011, diante das informações remetidas pelo Estado brasileiro e pelos peticionários, a $\mathrm{CIDH}$ revogou o objeto da medida, deixando de recomendar ao governo brasileiro a suspensão da obra, passando apenas a solicitar que o Brasil adotasse medidas de redução de impacto: 
1) Adote medidas para proteger a vida, a saúde e integridade pessoal dos membros das comunidades indígenas em situação de isolamento voluntário da bacia do Xingu, e da integridade cultural de mencionadas comunidades, que incluam ações efetivas de implementação e execução das medidas jurídico-formais já existentes, assim como o desenho e implementação de medidas específicas de mitigação dos efeitos que terá a construção da represa Belo Monte sobre o território e a vida destas comunidades em isolamento.

2) Adote medidas para proteger a saúde dos membros das comunidades indígenas da bacia do Xingu afetadas pelo projeto Belo Monte, que incluam (a) a finalização e implementação aceleradas do Programa Integrado de Saúde Indígena para a região da UHE Belo Monte, e (b) o desenho e implementação efetivos dos planos e programas especificamente requeridos pela FUNAI no Parecer Técnico 21/09, recém enunciados.

3) Garanta a rápida finalização dos processos de regularização das terras ancestrais dos povos indígenas na bacia do Xingu que estão pendentes, e adote medidas efetivas para a proteção de mencionados territórios ancestrais ante apropriação ilegítima e ocupação por não-indígenas, e frente à exploração ou ao deterioramento de seus recursos naturais. Adicionalmente, a CIDH decidiu que o debate entre as partes no que se refere à consulta prévia e ao consentimento informado em relação ao projeto Belo Monte se transformou em uma discussão sobre o mérito do assunto que transcende $\mathrm{o}$ âmbito do procedimento de medidas cautelares (CmIDH, 2011).

Segundo Beltrão, Oliveira e Pontes Junior (2014), a Comissão entendeu que a controvérsia não poderia mais ser sanada por medidas cautelares,

mas apenas por mecanismos de discussão sobre questões de mérito, que teriam, no fundo, duas prováveis intenções político-ideológicas: de apresentar, num futuro próximo, o caso à Corte, para que esta julgue se o Brasil é culpado ou não pela (não) garantia do direito à consulta dos povos indígenas no contexto da UHE Belo Monte; ou como forma de enfraquecer ou minimizar a própria atuação da Comissão, e da OEA 
de maneira geral, retirando a urgência de apreciação da Comissão (e da Corte) sobre o assunto, para que, com isso, o governo brasileiro diminua as reações político-econômicas impostas à OEA.

Cumpre salientar que a revogação da medida cautelar não se caracteriza como uma espécie de pedido de desculpa por parte da CIDH, menos ainda como possibilidade de extinção ou suspensão das medidas cautelares. Ocorreu, tão somente, a modificação do conteúdo, principalmente o desaparecimento da recomendação referente à suspensão imediata do processo de licenciamento da obra (Ventura; Cetra, 2013, p. 45).

Nessa linha, se realmente o debate ultrapassa o procedimento de medidas cautelares da $\mathrm{CmIDH}$, questiona-se se o caso não deveria ser de imediato levado à Corte Interamericana, porquanto não havendo a suspensão urgente da edificação, torna-se evidente que uma futura decisão da $\mathrm{CrIDH}$ a favor dos peticionários terá efeitos parcial ou totalmente prejudicados (Ventura; Cetra, 2013, p. 45).

Logo, em 27 de outubro de 2011, em Washington, na audiência que deveria discorrer sobre o caso, o Estado brasileiro não enviou nenhum representante. Foi a primeira omissão brasileira ante uma convocação do SIDH, e o já mencionado ministro de Minas e Energia, Edison Lobão, esclareceu que, primeiramente, a manifestação ocorrida deu-se pela comissão da OEA, além disso, considerou que o Brasil é um país soberano e que faz as coisas do modo correto, por isso "temos orgulho da matriz energética limpa e há de perseverar nela”. Por fim declarou que o país não está sujeito à intervenção de quem quer seja (Ventura; Cetra, 2013, p. 46).

Assim,

Na citada audiência, os invejosos em questão apresentaram, à CmIDH e a uma cadeira vazia, documentos que procuram comprovar a falta de consulta prévia às comunidades indígenas e a existência de novos casos de ameaças a lideranças, além do aumento exponencial de doenças entre indígenas e dos casos de violência no município de Altamira após 
o início das obras de Belo Monte. Manifestaram igualmente a expectativa de que "diante das ilegalidades do processo e do descumprimento de tratados internacionais e das determinações da CmIDH”, o Estado brasileiro fosse "levado à Corte" (Ventura; Cetra; 2013, p. 46) .

De acordo com a Conectas, a reação do governo aos questionamentos internacionais no caso da construção da Usina de Belo Monte são alarmantes, pondo em xeque sua política histórica de cooperação com o SIDH.

A difícil relação entre os direitos humanos e o imperativo do desenvolvimento é cotidiana, especialmente nos países do Sul global. A construção da Usina Hidrelétrica de Belo Monte é um exemplo emblemático dessa tensão. Em nossos países esse conflito está se resolvendo em favor de um suposto "crescimento econômico" e contra as comunidades diretamente afetadas. Belo Monte é um exemplo também de como essa tensão pode afetar toda a arquitetura de proteção dos direitos humanos: foi a adoção de medidas cautelares pela Comissão Interamericana de Direitos Humanos contra o Brasil no caso de Belo Monte que desencadeou a maior crise no Sistema Interamericano (Conectas, 2014).

Diante disso, percebe-se que foi a primeira vez que o Estado brasileiro reagiu de forma a desqualificar o sistema interamericano, argumentando no sentido de que recomendação da Comissão Interamericana soa como uma ingerência indevida no processo de desenvolvimento do país. Consequentemente percebe-se que o sistema interamericano atacou questões de interesses econômicos vultosos, gerando grandes tensões em torno do assunto, pois conforme analisado anteriormente, para assegurar os direitos humanos é necessário garantir a efetividade de seus mecanismos de proteção.

\section{CONCLUSÃO}

Foi sobretudo com a promulgação da Constituição de 1988 que o Estado brasileiro instituiu e concretizou uma estrutura jurídico-normativa de respeito aos valores basilares da dignidade humana. Reconheceu com 
isso o cerne dos direitos humanos em uma perspectiva universalizante, positivando-os no ordenamento jurídico pátrio por meio de um sistema de princípios e regras abrigados sob o manto do Estado Democrático de Direito.

Além da criação de um sistema constitucional de proteção aos direitos humanos fundamentais, o Brasil é também signatário de praticamente todas as convenções e tratados que integram o sistema internacional de direitos humanos da Organização das Nações Unidas (ONU) e da Organização de Estados Americanos (OEA), tendo, portanto, um posicionamento formal de respeito a estes direitos.

Esses instrumentos e tratados representam a garantia da conquista dos grupos sociais, culturais e políticos que não raro vivem em situação de exclusão, discriminação e opressão pela sociedade contemporânea, de perfil fortemente capitalista e de exclusão cultural.

Nesses termos, o processo histórico do Sistema Interamericano de Direitos Humanos tem sido uma importante ferramenta de tutela desses direitos em toda a América, entretanto nem sempre se mostra eficaz, tendo em vista a sua parca força política para se sobrepor aos interesses soberanos dos Estados que a compõem.

Diante das reflexões desenvolvidas no presente trabalho, sobretudo quando analisado o direito à identidade cultural, foi possível apurar que o projeto da Usina Hidrelétrica de Belo Monte ameaçava, e ainda ameaça, impactar irremediavelmente a vida e a integridade dos indígenas e ribeirinhos que ali vivem, tendo em vista o deslocamento forçado, a insegurança alimentar e hidrológica, o aumento de doenças, ameaças de invasões às terras indígenas e o aproveitamento ilegal de recursos naturais, assim como o aumento da pobreza e a migração desordenada, que sobrecarregará os sistemas de saúde, educação e segurança pública. 
Por conseguinte, verificou-se que apesar da gravidade e irreversibilidade dos impactos da obra para as comunidades locais, não foram concretizadas as medidas adequadas para garantir a proteção dos direitos das comunidades afetadas e nem do meio ambiente.

A complexidade desse caso, todavia, não se esgota na cena internacional, visto que também pode ser analisado a partir da perspectiva doméstica. No âmbito internacional, observou-se que a CIDH inovou em seu foco de atuação, passando a agir em questões que correspondem às demandas apresentadas pela nova ordem global, como é caso da construção de empreendimentos que afetem os direitos das minorias e ao meio ambiente, sobretudo quando recomendou ao Estado brasileiro a adoção da medida cautelar 382/2010.

No âmbito doméstico observou-se que, considerando a quantidade de interesses envolvidos no caso de Belo Monte, o governo brasileiro, mesmo após a recomendação da medida cautelar 382/2010, decidiu, a despeito do compromisso assumido diante do Sistema Interamericano de Direitos Humanos, dar continuidade à construção de Belo Monte ainda com as mesmas irregularidades apontadas. Além do mais, em sua resposta manifestou-se no sentido de que o Estado brasileiro é soberano e, portanto, não precisa de submeter às intervenções da OEA.

Especificamente neste caso, foi possível reconhecer claramente a abstenção do Estado brasileiro perante os tratados internacionais de direitos humanos dos quais é signatário, quando priorizou a supremacia da satisfação dos interesses econômicos em detrimento da proteção dos direitos humanos.

Por fim, verificou-se que diante das respostas emitidas pelo Estado brasileiro ao sistema interamericano, a medida cautelar 382/2010 teve o teor de seu conteúdo modificado. Analisando tal fato, é possível afirmar que tais modificações decorreram de influências políticas e econômicas, 
em especial às declarações do ministro de Minas e Energia, Edison Lobão, do ministro das Relações Exteriores, da ministra Maria do Rosário, assim como da manifestação oficial do Partido Comunista do Brasil (PCdoB).

Ademais, outras medidas político-administrativas foram tomadas no mesmo sentido, como se observa na decisão de remover o juiz federal de Altamira, Antonio Carlos de Almeida Campelo, a concessão das licenças ambientais pelo Ibama mesmo ante as irregularidades apontadas pelos técnicos do próprio Instituto, bem como perante a precariedade do atendimento às condicionantes exigidas.

Foi possivel reconhecer, entretanto, que a revogação da supramencionada medida não torna o SIDH menos eficaz, pois o Estado brasileiro já havia sofrido outras condenações perante a Corte Interamericana de Direitos Humanos. Assim, apesar de suas limitações, o Sistema Interamericano de Direitos Humanos tem cumprido a função para a qual foi criado, atuando de forma efetiva nos casos de violação aos direitos humanos no contexto dos países latino-americanos. Essa atuação, muito embora, em muitos casos, esbarre no princípio da soberania nacional dos Estados-partes, sempre gera tensões internas que fortalecem o debate indispensável para construção de uma sociedade que parece utópica, mas que na verdade é a sociedade que foi idealizada quando, em 1948, foi promulgada a Declaração Universal de Direitos Humanos.

\section{REFERÊNCIAS}

ASSOCIAÇÃO INTERAMERICANA PARA DEFESA DO AMBIENTE. Guia de defesa ambiental. Construindo a estratégia para o litígio de casos diante do Sistema Interamericano de Direitos Humanos, 2010. Disponível em: <http:// www.aida-americas.org/sites/default/files/refDocuments/GUIA\%20AIDA\%20 PORTUGUES.pdf>. Acesso em: 23 abr. 2014. 
BELTRÃO, Jane; OLIVEIRA, Assis; PONTES JUNIOR, Felicio. Significados do direito à consulta: povos indígenas versus UHE Belo Monte, 2014. Não publicado.

BRASIL. Constituição (1988). Constituição da República Federativa do Brasil. 35. ed. São Paulo: Saraiva, 2005. Atualizada até emenda 45/04.

BRASIL. Decreto $n^{\circ} 788$, de 13 de julho de 2005. Autoriza o Poder Executivo a implantar o Aproveitamento Hidrelétrico Belo Monte, localizado em trecho do Rio Xingu, no Estado do Pará, a ser desenvolvido após estudos de viabilidade pela Centrais Elétricas Brasileiras S.A. - Eletrobrás. Disponível em: <http:// legis.senado.gov.br/legislacao/ListaTextoIntegral.action?id=231371>. Acesso em: 23 abr. 2014a.

BRASIL. Ministério das Relações Exteriores. Solicitação da Comissão Interamericana de Direitos Humanos (CIDH) da OEA. Nota à imprensa $\mathrm{n}^{\circ} 142$. Brasília, 5 de abril de 2011. Disponível em: <www.itamaraty.gov.br>. Acesso em: 28 mar. 2014b.

BUTZKE, Arlindo. Ação popular como exercício da cidadania socioambiental: estudo de caso da Usina Belo Monte. Revista de Direito Ambiental, ano 18, v. 69, jan./mar. 2013.

COMISSÃO INTERAMERICANA DE DIREITOS HUMANOS. MC 382/10. Comunidades Indígenas da Bacia do Rio Xingu, Pará, Brasil, de $1^{\circ}$ de abril de 2011. Texto completo disponível em: <http://www.xinguvivo.org.br/wpcontent/uploads/2010/10/Carta_otorgamiento corregida_peticionario1.pdf> Acesso em: 25 mar. 2014.

CHIRIBOGA, Oswaldo Ruiz. O direito à identidade cultural dos povos indígenas e das minorias nacionais: um olhar a partir do Sistema Interamericano. SUR - Revista Internacional de Direitos Humanos, São Paulo, ano 3, n. 5, p. 43-67, 2006.

CONECTAS. Desenvolvimento não é expansão do consumo. Disponível em: $<\mathrm{http}$ ///www.conectas.org/pt/acoes/sur/noticia/o-fator-economico>. Acesso em: 28 abr. 2014. 
JUSTIÇA GLOBAL. "Belo Monte: Após boicotar audiência, Brasil é cobrado na CIDH/OEA”, Destaque, 28/10/2011. Disponível em: <http://global.org.br/ programas/belo-monte-apos-boicotar-audiencia-brasil-e-cobrado-na-cidhoeaq $>$. Acesso em: 22 mar. 2014.

MOREIRA, Eliane. O direito dos povos tradicionais à consulta prévia, livre e informada. In: DIAS, Jean Carlos; GOMES, Marcos Alan de Melo (Coord.). Direito e Desenvolvimento. Rio de Janeiro: Forense; São Paulo: Método, 2014. p. 113-134.

ORGANIZAÇÃO DOS ESTADOS AMERICANOS. Convenção Americana de Direitos Humanos, 22 de novembro de 1969. San José de Costa Rica. Disponível em: <https://www.cidh.oas.org/Basicos/Portugues/u.Regulamento. CIDH.htm>. Acesso em: 14 abr. 2014.

PEIXOTO, Erica de Souza Pessanha. Universalismo e relativismo cultural. Revista da Faculdade de Direito de Campos, ano VIII, n. 10, p. 260-272, jun. 2007.

PONTES, Felício Jr. Belo Monte: uma década de violência contra a lei, o meio ambiente e o ser humano. In: MERLINO, Tatiana (Coord.). Direitos Humanos no Brasil 2011. Relatório da Rede Social de Justiça e Direitos Humanos. São Paulo: Rede Social de Justiça e Direitos Humanos, 2011, p. 103-110.

SENA, Beatriz Veríssimo de. Reexame judicial de políticas públicas: caso da construção da Usina Belo Monte. Fórum Administrativo - FA, Belo Horizonte, ano 12, n. 135, p. 40-59, maio 2012.

SENADO FEDERAL. Requerimentos números 573 e 574. Diário do Senado Federal de 10/06/2011, p. 22.954-22.955.

SILVA, Roberta Soares da. Direitos humanos e o sistema internacional de proteção no século XXI - o desenvolvimento como condição para a pacificação social. Revista Brasileira de Direitos Humanos, Porto Alegre, ano 1, v. 2, n. 2, p. 53, jul./set. 2011. 
UNESCO. Convenção de 2003 para a Salvaguarda do Patrimônio Cultural Imaterial, 17 de outubro de 2003. Paris. Disponível em: <http://unesdoc.unesco. org/images/0021/002181/218142por.pdf>. Acesso em: 28 abr. 2014.

VENTURA, Deisy; CETRA, Ortiz Raísa. O Brasil e o sistema interamericano de direitos humanos: de Maria da Penha a Belo Monte. In: FILHO, José Calos Moreira da Silva; TORELLY, Marcelo (Orgs.). Justiça de transição nas Américas: olhares interdisciplinares, fundamentos e padrões de efetivação. Belo Horizonte: Forum, 2013.

Recebido em: 7/8/2014

Aceito em: 29/8/2014 